\begin{tabular}{|l|l|l||}
\hline \multicolumn{2}{|c|}{ PublisherInfo } \\
\hline \hline PublisherName & $:$ & BioMed Central \\
\hline \hline PublisherLocation & $:$ & London \\
\hline \hline PublisherImprintName & $:$ & BioMed Central \\
\hline \hline
\end{tabular}

\title{
Treatment of murine lupus with cDNA encoding IFN-?R/Fc
}

\begin{tabular}{|l|l|l||}
\hline \multicolumn{2}{|c|}{ ArticleInfo } \\
\hline \hline ArticleID & $:$ & 156 \\
\hline \hline ArticleDOI & $:$ & $10.1186 /$ ar-2000-66840 \\
\hline \hline ArticleCitationID & $:$ & 66840 \\
\hline \hline ArticleSequenceNumber & $:$ & 113 \\
\hline \hline ArticleCategory & $:$ & Paper Report \\
\hline \hline ArticleFirstPage & $:$ & 1 \\
\hline \hline ArticleLastPage & $:$ & 3 \\
\hline \hline & & RegistrationDate : 2000-9-12 \\
\hline ArticleHistory & $:$ & OnlineDate \\
\hline \hline ArticleCopyright & $:$ & Current Science Ltd2000-9-12 \\
\hline \hline ArticleGrants & $:$ & \\
\hline \hline ArticleContext & $:$ & 130753311 \\
\hline \hline
\end{tabular}




\section{Keywords}

IFN-?, lupus,Fc fusion protein, IFN-?R, plasmid gene therapy

\section{Context}

Increased levels of IFN-? have been observed in both lupus-prone mice and humans and are thought to be central to disease progression: lupus-prone mice treated with IFN-? exhibit accelerated disease, whereas those treated with an anti-IFN-? antibody have a delayed disease onset. Furthermore, deletion of either the IFN-? or IFN-? receptor (IFN-?R) genes in lupus-prone mice significantly decreases the humoral and histological characteristics of the disease. The present study describes a novel therapeutic intervention whereby the disease-promoting effects of IFN-? are blocked by the expression of an IFN?R/IgG1Fc fusion protein. To evaluate whether intramuscular injections of a plasmid containing cDNA that encodes IFN-?R/IgG1Fc can retard lupus development and progression in lupus-prone mice.

\section{Significant findings}

MRL-Fas ${ }^{1 p r}$ mice were injected with either VR1255-IFN-?R/Fc or VR1255 plasmids at monthly intervals up to 6 months of age and then bimonthly. Serum levels of IFN-?R/Fc in mice injected without electroporation were undetectable 6 weeks after two injections, whereas those injected together with electroporation exhibited a mean level of $144 \mathrm{ng} / \mathrm{ml}$. The in vivo blocking activity of the expressed receptor was ascertained by measuring serum IFN-? levels at the time of death. Mice injected with the active plasmid without electroporation had half the level of IFN-? compared to control animals, while injection of the active plasmid plus electroporation reduced IFN-? levels to $10-25 \%$. A survival rate of $100 \%$ was observed at 14 months where the injections plus electroporation were initiated at 4 months (diseased), while this dropped to $90 \%$ when initiated at 1 month (pre-disease). Injection of the active plasmid plus electroporation at 4 months resulted in a significant reduction in the levels of both polyclonal IgG2a and anti-chromatin autoantibody subclass IgG2a. Lymphoid hyperplasia, glomerulonephritis and blood urea nitrogen levels were reduced in treated animals and fewer infiltrating macrophages and T cells were observed within the kidneys. Decreased kidney IgG deposits together with lower expression of MHC class II, ICAM-1 and MCP-1 were also noted in the active plasmid treated mice. 


\section{Comments}

This study involves the injection of plasmid cDNA encoding the fusion protein, IFN-?R/Fc, in an attempt to prevent the development and progression of autoimmune disease in lupus-prone mice. It makes an important contribution to the development of gene therapy in treating autoimmune disease and is of considerable interest for a number of reasons: it demonstrates that effective blocking of IFN-? signalling results in dramatically improved renal pathology and mortality rates in mice both before onset of disease and, more importantly, at advanced stages disease. In addition it underlines the efficacy of nonviral vectors and demonstrates that electroporating at the injection site can vastly improve the efficiency of DNA transfer, resulting in an increase in the survival rate from $62 \%$ to $90 \%$. Therefore, this novel strategy used to inhibit IFN-? is an excellent candidate for therapeutic development and may well be applicable for use in treating other autoimmune diseases.

\section{Methods}

The extracellular portion of mouse IFN-?R a-chain and IgG1 constant heavy-chain cDNA were generated by RT-PCR and used to generate a full-length IFN-?R/IgG1Fc cDNA segment by PCR. This fragment was then inserted into the VICAL VR1255 vector. Plasmid DNA was prepared by the alkali lysis method. Anaesthetized MRL-Fas ${ }^{\mathrm{lpr}}$ mice were injected with either VR1255-IFN-?R/Fc or VR1255 plasmids into both tibialis anterior muscles. Electroporation was carried out using a pair of electrode needles, which were inserted into the muscle bed $5 \mathrm{~mm}$ apart on either side of the injection site. IgG subclasses and serum IFN-?R/Fc fusion protein levels were measured by ELISA. Intracellular IFN-? was measured FACs analysis of permeabilized cells and MHC class II, ICAM-1, MCP-1 F4/80 and CD3 expression in the kidneys was determined by immunocytochemical analysis.

\section{References}

1. Lawson BR, Prud'homme GJ, Chang Y, Gardner HA, Kuan J, Kono DH, Theofilopoulos AN: Treatment of murine lupus with cDNA encoding IFN-?R/Fc. J Clin Invest. 2000, 106: 207-215.

This PDF file was created after publication. 